\title{
Processing strategy and distraction affect reaction time and the $\mathrm{CNV}$
}

\author{
STEPHEN P. KIRST and JACKSON BEATTY \\ University of California, Los Angeles, California 90024
}

\begin{abstract}
Subjects used two attentional sets for a reaction time (RT) task in which the information necessary for correct performance was divided between the warning (S1) and the imperative (S2) stimuli. In the general preparation set both right and left forefingers were to be prepared equally for the response. In the specific preparation set either the right or left forefinger was to be primed differentially on the side indicated by $\mathrm{S} 1$; thus, S2 matched a subject's preparation on only $50 \%$ of these trials. During half of all the trials a visual distractor was randomly presented. Dependent variables were RT and the contingent negative variation (CNV). Both set and distraction affected RT and the CNV, with larger negative shifts and faster RTs associated with the specific set. While the effect of distraction on performance was reduced under the specific set, the CNV was insensitive to this interaction, attenuating equally to distraction in both sets.
\end{abstract}

\section{METHOD}

\section{Subjects}

The 20 subjects were paid right-handed male volunteers enlisted from university undergraduate psychology classes. Two subjects were excluded from the final analyses following a computer failure that resulted in data loss.

\section{Recording \\ Beckman miniature biopotential electrodes $(\mathrm{Ag}: \mathrm{AgCl})$ were attached to each subject at $\mathrm{Fz}, \mathrm{Cz}, \mathrm{Pz}$, and $\mathrm{Oz}$, and referenced to linked-ear electrodes with the electrooculogram (EOG) recorded diagonally across the right eye. The subject was grounded at the mastoid. Interelectrode impedance was less than $5 \mathrm{Kohms}$ at $30 \mathrm{~Hz}$. A low-noise preamplifier $($ Gain $=100$, time constant $=$ $10 \mathrm{sec})$ first amplified all signals before amplification by a Beckman R411 dynograph (DC, $30 \mathrm{~Hz}$ ). EEG and EOG were sampled at $10-\mathrm{msec}$ intervals and stored on disk by a general- purpose computer (Hewlett-Packard 2116B). Because of limited access to computing time, only the full analysis of the vertex data is reported in this paper.}

\section{Eye Movements}

EOG artifact was controlled by requiring fixation during each trial and by visual inspection of the EOG after each trial; thus, on-line rejection of EOG-contaminated trials was a feature of the operating system. The mean rejection percentage for eye move-

This article is based on the doctoral thesis of the first author. Special thanks to Barbara Henker for her valuable insights during the course of this study as well as to the other committee members, David Shapiro, Joaquin Fuster, and Donald Lindsley. Technical assistance was provided by Perry Jaster; computer programming was done by Carl Figueroa and David Goodman. The research was supported by the Advanced Research Projects Agency of the Department of Defense under Contract N0001470-C-0350. Computer processing for data analysis was provided by the Center for Computer-Based Behavioral Studies under Contract F30602-70-00016 with the Advanced Research Projects Agency of the Department of Defense. Requests for reprints should be sent to Dr. Stephen P. Kirst, 1100 Glendon Avenue, Suite 1737, Los Angeles, California 90024. ment, calculated as the ratio of rejected trials to the total number attempted, was $16.2 \%$.

\section{Procedure}

The isolated experimental room was dimly illuminated and wide-band acoustic noise masked extraneous sound. The subject and experimenter communicated by intercom and closed-circuit television. The subject was seated in a chair with two large armrests, each with a computer-illuminated solid state switch. A trial could not begin unless the subject was depressing both switches ( $150 \mathrm{~g}$ required pressure).

Each trial (Figure 1A) of $4.5 \mathrm{sec}$ involved a prewarning stimulus epoch before $\mathrm{S} 1$ of $1,000 \mathrm{msec}$, an interstimulus interval between $\mathrm{S} 1$ and $\mathrm{S} 2$ of $1,500 \mathrm{msec}$, and a postimperative stimulus (S2) epoch of $2,000 \mathrm{msec}$. S1 was the word RIGHT or LEFT, and S2 was SAME or DIFF, each presented for $40 \mathrm{msec}$ in the center of the display $(1.5 \times 3 \mathrm{~cm})$; at the end of the trial the subject was given RT feedback on his performance in milliseconds as a four-digit display. RT feedback was given only for errorless trials; when the subject made any mistake, the computer-controlled switches flashed to signal a response error. The intertrial interval varied randomly from 10 to $25 \mathrm{sec}$. The subject's task was to respond to "SAME" by lifting his forefinger from the button designated by $\mathrm{S} 1$ and to "DIFF" by lifting his forefinger from the other button. The actual data acquisition averaged $1 \mathrm{~h}$.

On $50 \%$ of the trials, a distractor appeared at the onset of S1 and continued until the end of the trial. The distractor stimulus was a five-space rotating display with a $100-\mathrm{msec}$ cycle time of the words RIGHT, LEFT, SAME, or DIFF which appeared less than $2 \mathrm{~mm}$ above $\mathrm{S} 1$ and $\mathrm{S} 2$. The effect of the display was as follows: RIGHT, $\cdot$ RIGH, T·RIG, FT·RI, EFT $\cdot$ R, LEFT $\cdot$, LEFT, E.LEF, ME LE, AME L, SAME-, and so on. In the nondistracting condition, an illuminated dot in the same place and of the same total duration as the distractor stimulus was used to control for the temporal information contained in the distractor, which in effect constituted an additional S1 continuing through to feedback.

\section{Performance Strategies}

The subject was instructed in two sets for the task. The first was described to him as a general preparation set. For this he prepared both right and left forefingers equally, awaiting the 
A

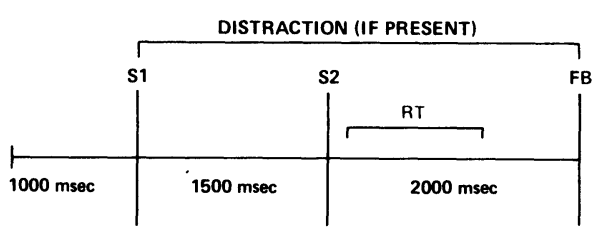

S1 = RIGHT OR LEFT (40 msec)

S2 = SAME OR DIFFERENT $(40 \mathrm{msec})$

$\mathrm{FB}=$ FEEDBACK ON RT

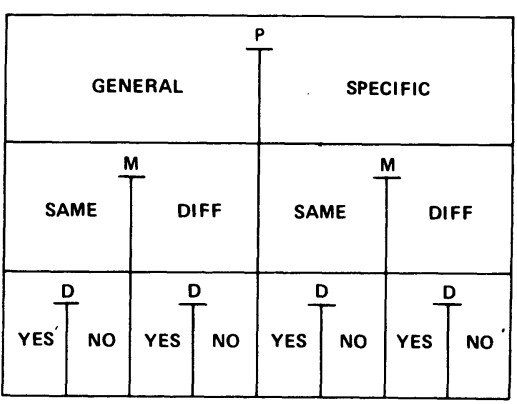

$P=$ PROCESSING SET
$M=$ MATCH

D = DISTRACTION

Figure 1. (A) An event model of a trial. (B) The experimental design.

presentation of both S1 and S2 before lifting the correct forefinger as quickly as possible. The second was described to the subject as a specific preparation set. For this he prepared either the right or left forefinger, depending on which side was indicated by S1. Thus, he was instructed to act as if the S2 would be SAME. When DIFF appeared, he would have to inhibit the prepared response and initiate a movement in the other hand. For the general set, then, the subject was not to prepare either side differentially, while for the specific set he prepared the response indicated by $S 1$.

Following an initial practice period, data were obtained in four blocks of 16 errorless trials, yielding 64 trials for each subject. Each combination of S1, S2, and distractor was equally probable (Figure 1B); individual trials were randomized within each block. Processing set was counterbalanced across subjects and within individual subjects (general-specific-specific-general or specific-general-general-specific).

\section{RESULTS}

For the purpose of data analysis, the RIGHT-LEFT dimension was collapsed (see Donchin, Kutas, \& Johnson, 1974), and both RT and EEG data were averaged over the resulting eight trials in each condition. The mean of the 1,000-msec pre-S1 epoch (100 points) was used as a relative baseline, and the CNV itself was computed as the mean negative shift in microvolts during the $750-\mathrm{msec}$ interval (M750) prior to S2. This measure was chosen to encompass the major portion of the CNV waveform.

The specific set speeded RT overall by $71 \mathrm{msec}$ $[\mathrm{F}(1,17)=20.170, \mathrm{p}<.001]$, whereas distraction delayed RT by $32 \mathrm{msec}[\mathrm{F}(1,17)=10.938, \mathrm{p}<.001]$. The Set by Match interaction (Figure 2) was highly significant $[F(1,17)=18.075, p<.001]$, with most of the decrease in RT for the specific set contained in the SAME condition $(106 \mathrm{msec})$ as compared to the DIFF condition $(32 \mathrm{msec})$. Figure 2 presents the RTs obtained under the various conditions of the experiment.

The Set by Distraction interaction was marginally significant $[F(1,17)=3.931, p<.10]$, with the distractor increasing RT by 42 msec in the general set but by $20 \mathrm{msec}$ in the specific set. There was also a greater subject error rate in the presence of the distractor in the general than in the specific set $(59 \%$ vs. $41 \%)$ (chi square $=7.6133, \mathrm{df}=3, \mathrm{p}<.10$ ).

The main effects of set and distraction were significant for the CNV. The specific preparation set increased the mean negative amplitude by $3.4 \mathrm{mV}$ (from 7.5 to 10.9) $[F(1,17)=18.516, p<.001]$, while the distractor attenuated mean negativity by $1.9 \mathrm{mV}$ (from 10.2 to 8.3) $[F(1,17)=5.565, p<.05]$. There was no interaction of set and distraction for the CNV $[F(1,17)=.189$, n.s.]. Figure 3 presents the EOG and EEG at $\mathrm{Cz}$ averaged across the 18 subjects for each of the eight conditions.

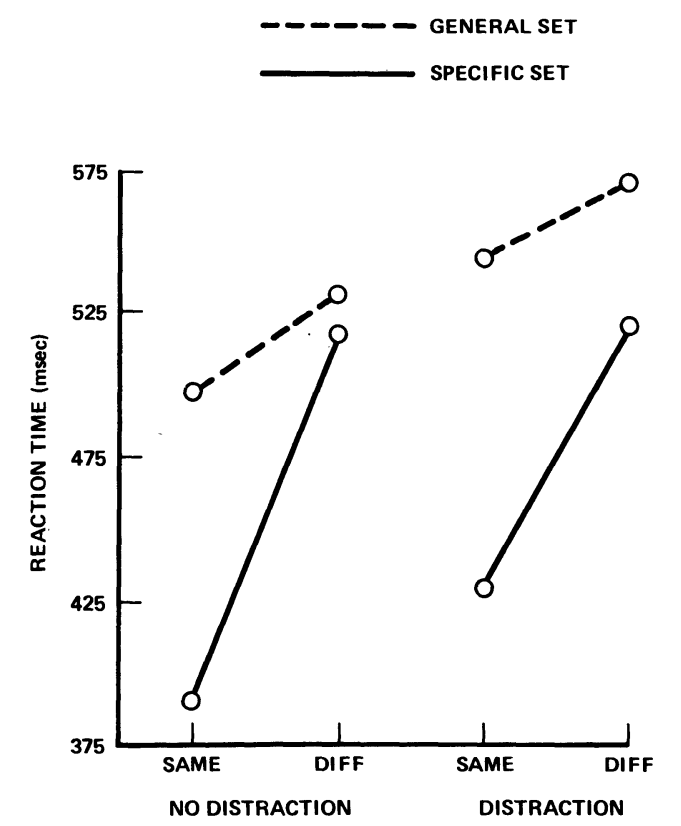

Figure 2. The interaction of set and match for RT. 


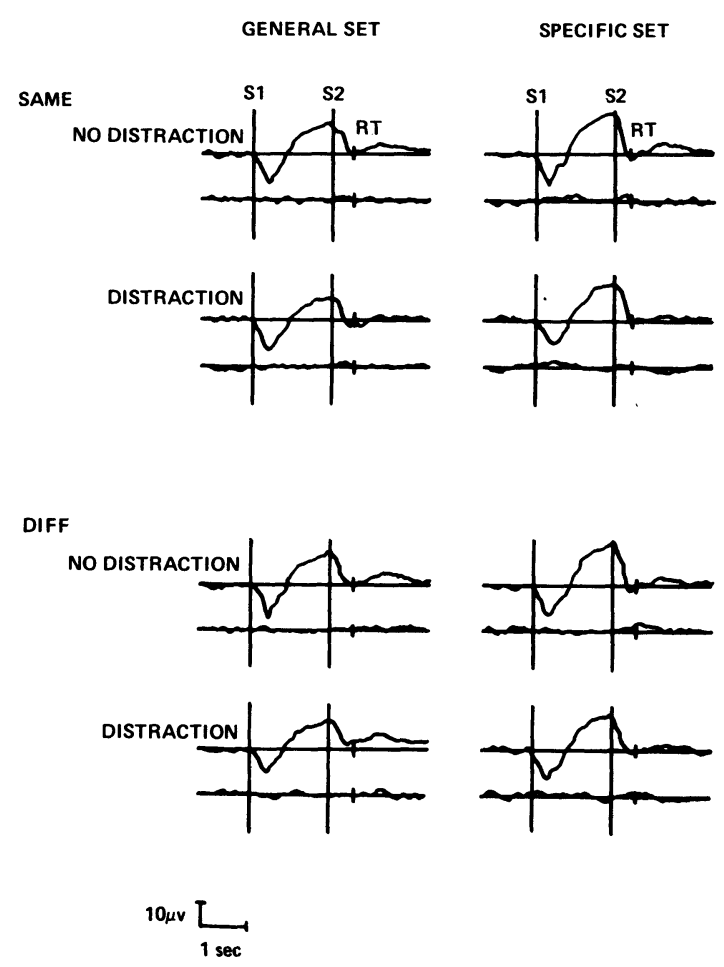

Figure 3. The vertex EEG and EOG averaged across 18 subjects for each of the eight conditions (negative up).

Since it appeared that the CNV paralleled RT for the main effects of set and distraction, but not for the interaction, a further analysis was performed to test for the interaction in a subgroup of the experimental population. Only those subjects whose RT exhibited a strong distractibility effect under the general processing set, but a weak or nonexistent effect under the specific processing set, were included in this test. An ANOVA on this group of eight subjects showed that, while both RT and the CNV were significantly affected by set $(p<.05$ and $p<.01$, respectively) and by distraction $(p<.001$ and $\mathrm{p}<.07$, respectively), the CNV completely failed to follow the Set by Distraction interaction $[F(1,17)=$ .024 , n.s.] that was so powerful, by selection, for RT $[F(1,17)=42.179, \mathrm{p}<.001]$.

\section{DISCUSSION}

The changes in performance under the two conditions of instruction suggest that they effectively led to different cognitive processing sets, which were accompanied by changes in the CNV similar to those reported by Loveless and Sanford (1974). A stumbling block in previous simple RT research (Loveless \& Sanford, 1974; Woodworth \& Schlosberg, 1954) was the reported difficulty in subjects adopting a sensory set after performing under response set instructions, thus preventing counterbalancing of set within subjects. Apparently the task in the present experiment was sufficiently complex to allow subjects to adopt different cognitive strategies toward the same experimental stimuli in either order. Under these conditions, RT performance and the CNV accompanied changes in processing set, with the faster RTs following the larger CNVs in the specific preparation set and slower RTs following smaller CNVs in the general preparation set.

This view is complicated, however, by the analysis of distraction and its interaction with set. In the present study, the specific set forced subjects to assume a particular response rule for acting on the stimulus information in S1 prior to the input of the actual response rule in S2. A consequence of this preparatory set was the selective suppression of the behavioral effects of distraction. The RT and the response error data support the conclusion that the specific set demonstrated greater efficiency of processing, as indicated by reduced susceptibility to distraction. However, the CNV, in contrast to RT, was attenuated greatly by distraction regardless of set.

That the vertex CNV did not parallel the behavioral interaction between set and distraction, while at the same time paralleling the main effects, suggests that all the cortical processes determining RT are not indexed by the CNV; this may be especially the case when extraneous demands such as distraction complicate the information-processing task. Thus, it is not surprising that simple relations between RT and the CNV waveform have not always been observed (Rebert \& Tecce, 1973).

\section{REFERENCES}

Donchin, E., Kutas, M., \& Johnson, R., JR. The CNV does not behave like a "motor" potential. Electroencephalography and Clinical Neurophysiology, 1974, 37, 434.

LOVElESS, N. E., \& SANFord, A. J. Slow potential correlates of preparatory set. Biological Psychology, 1974, 1, 303-314.

REBERT, C. S., \& TECCE, J. J. A summary of CNV and reaction time. Electroencephalography and Clinical Neurophysiology, 1973, 33, 173-178. (Supplement)

WOODWORTH, R. S., \& SCHLOSBERG, H. Experimental psychology. New York: Holt, Rinehart, \& Winston, 1954.

(Received for publication April 12, 1978.) 